\title{
ANTLER CYCLE AND ENDOCRINE PARAMETERS IN MALE AXIS DEER ( $A X I S$ AXIS): SEASONAL LEVELS OF LH, FSH, TESTOSTERONE, AND PROLACTIN AND RESULTS OF GnRH AND ACTH CHALLENGE TESTS
}

\author{
G. A. BubeniK, * R. D. Brown $†$ and D. SCHAms $\ddagger$ \\ *Department of Zoology, University of Guelph, Guelph, Ontario, Canada, N1G 2W1, \\ Telephone: (519) 824-4120; $†$ Department of Wildlife and Fisheries, Mississippi State University, \\ Mississippi State, MS 39762, U.S.A.; †Department of Physiology, Technical University \\ Munchen-Weihenstephan, D-805 Freising, F.R.G.
}

(Received 31 October 1990)

\begin{abstract}
Antler cycles of six adult male axis deer of southern Texas were relatively well synchronized within the herd. The old antlers were cast from December to March and regenerated antlers polished between March and June. The rutting season occurred in June and July.

2. LH and FSH exhibited little seasonal variation (LH $0.7-1.3 \mathrm{ng} / \mathrm{ml}$; FSH $32-65 \mathrm{ng} / \mathrm{ml}$ ). Prolactin levels were lowest in December $(20 \mathrm{ng} / \mathrm{ml})$ and highest in June $(115 \mathrm{ng} / \mathrm{ml})$. Testosterone concentrations exhibited a distinct seasonal pattern: minimum in December $(0.1 \mathrm{ng} / \mathrm{ml})$ and maximum in May $(1.75 \mathrm{ng} / \mathrm{ml})$.

3. After GnRH challenge ( $100 \mu \mathrm{g}$ given i.m. in November), maximal LH levels (reached 40-60 min after injection), varied from 7.7 to $11.2 \mathrm{ng} / \mathrm{ml}$, and $\mathrm{T}$ levels varied from 1.3 to $1.6 \mathrm{ng} / \mathrm{ml}$.

4. Twenty I.U. of ACTH (given in March), elevated cortisol levels from 4-8 $\mu \mathrm{g} / \mathrm{dl}$ (pretreatment) to $16-21 \mu \mathrm{g} / \mathrm{dl}$ (140 min post-administration).
\end{abstract}

\section{INTRODUCTION}

The seasonal variability of reproductive hormones in boreal deer species correlates with the antler cycle (Lincoln, 1985; Bubenik, 1986). On the other hand the antler cycle of tropical deer species, such as the rusa deer (Cervus rusa timorensis), axis deer (Axis axis), or muntjack (Muntiacus muntjac) appears to be aseasonal in most of their native habitat (Morris, 1935; Van Bemmel, 1952; Asdell, 1964), but populations transplanted into temperate regions may remain aseasonal (Mohr, 1932; Loudon and Curlewis, 1988) or exhibit seasonality with relatively good synchronization of the antler cycle (Ables, 1977; van Mourik and Stelmasiak, 1990; Chapman and Harris-personal communication). In order to elucidate the relationship between antler cycles and reproduction, seasonal levels of LH, FSH, testosterone (T) and prolactin (PRL) as well as LH and T after GnRH administration were investigated in adult male axis deer in southern Texas. In addition, to investigate the readiness of the pituitary-adrenal axis to respond to simulated stress, an ACTH challenge test was applied to three bucks.

\section{MATERIALS AND METHODS}

\section{Animals and sampling procedures}

Seven male axis deer (Axis axis) ranging in age from 1 to 4 years were obtained from an exotic animal farm located $40 \mathrm{~km}$ north of San Antonio, Texas and then transferred $300 \mathrm{~km}$ south to Kingsville, Texas (latitude 27:3 N). The animals were fed pelleted, standard deer ration supplemented by fresh sorghum plants and branches of deciduous trees. Between November and June all bucks were immobilized monthly $(0800-0900 \mathrm{hr})$ by a $1: 1$ mixture of Rompun (xylazine hydrochloride) and Ketaset (ketamine hydrochloride) (2-3 mg/kg, combined dose). After achieving sufficient sedation, three samples were collected $10 \mathrm{~min}$ apart from the jugular vein into pre-heparinized tubes. Blood was kept on ice until it was centrifuged (usually within $1 \mathrm{hr}$ ); plasma was then separated and frozen for later assays. Unfortunately we were not able to complete the entire year cycle because of the loss of two bucks during the summer heat.

At the end of November of the following year, three adults males (A, B and C), from the previous study were similarly immobilized and a Tefion coated catheter (Cathlon, Criticon Corp., Markham, Ontario, Canada) was inserted into the jugular vein for serial sampling. After three samples $(20 \mathrm{ml}$ each) were taken $10 \mathrm{~min}$ apart, $100 \mu \mathrm{g}$ of GnRH (Hoechst Co., F.R.G.) was injected i.m.; seven more samples then followed, taken $30 \mathrm{~min}$ apart.

The following March these bucks were immobilized again and cannulated. After three samples were taken $10 \mathrm{~min}$ apart, 20I.U. of porcine ACTH (ACTHAR, Armour Pharm. Co. U.S.A.) was injected i.m. Three more samples were then withdrawn $10 \mathrm{~min}$ apart, three others $20 \mathrm{~min}$ apart, and the last three samples $30 \mathrm{~min}$ apart.

\section{Radioimmunoassays}

LH was determined by a homologous bovine assay with no crossreactivity to other pituitary hormones. The sensitivity was $0.5 \mathrm{ng} /$ tube; intra-assay coefficient of variation (CV) averaged $8.6 \%$, and interassay variation was $11.5-19 \%$. FSH was determined by a system where pure ovine FSH was used for labelling, and the antiserum against ovine FSH was produced in guinea pigs. The sensitivity was $5 \mathrm{ng} /$ tube, intra-assay $\mathrm{CV}$ was $7.5 \%$, and interassay $\mathrm{CV}$ was $12-18 \%$. Prolactin was determined by a homologous bovine assay. The antiserum produced in rabbits showed no crossreactivity to other pituitary hormones. The sensitivity was $0.05 \mathrm{ng} /$ tube, intra-assay $\mathrm{CV}$ was $8.4 \%$ and the interassay $\mathrm{CV}$ was $14 \%$. Testosterone was determined by a highly specific assay. The sensitivity was $50 \mathrm{pg} / \mathrm{ml}$. The interassay CV was $7.5-12 \%$. Cortisol levels were measured by a highly 
specific radioimmunoassay (RIA Inc. Scarboro, Ontario, Canada). The sensitivity was $0.5 \mu \mathrm{g} / \mathrm{dl}$. Intra-assay and interassay CVs were less than 10\%. Details of all RIA were described previously (Bubenik el al. 1983; Smith and Bubenik, 1990).

\section{Anter cucle}

Antler length was measured with flexible tape, and frontal and lateral photographs were taken of each deer.

\section{Evaluation}

The mean of three conseculive samples was used for each month to construct individual curves of seasonal fuctuations of LH, FSH, PRL and T, A standard error was then calculated for each monthly group. As two of our bucks polished antlers 1 month ahead of the others, it was decided to shift their hormone and antler curves ahead for analysis purposes. Thus constructively hormonal levels of all animals could be compared with the corresponding phases of their individual antler cycles. Response curves were constructed from individual values of experiments utilizing $\mathrm{GnRH}$ and ACTH.

\section{Statistical analysis}

In the seasonal study, the monthly means were evaluated by analysis of variance (ANOVA). The significance of month factors was then assessed by a two-tailed Student's test. The significance of $P<0.05$ was accepted.

\section{RESULTS}

\section{Seasonal levels}

The levels of $\mathrm{LH}$ and FSH did not exhibit significant variation $(P>0.05)$ throughout the 8 month sampling period (Fig. 1). On the other hand PRL and
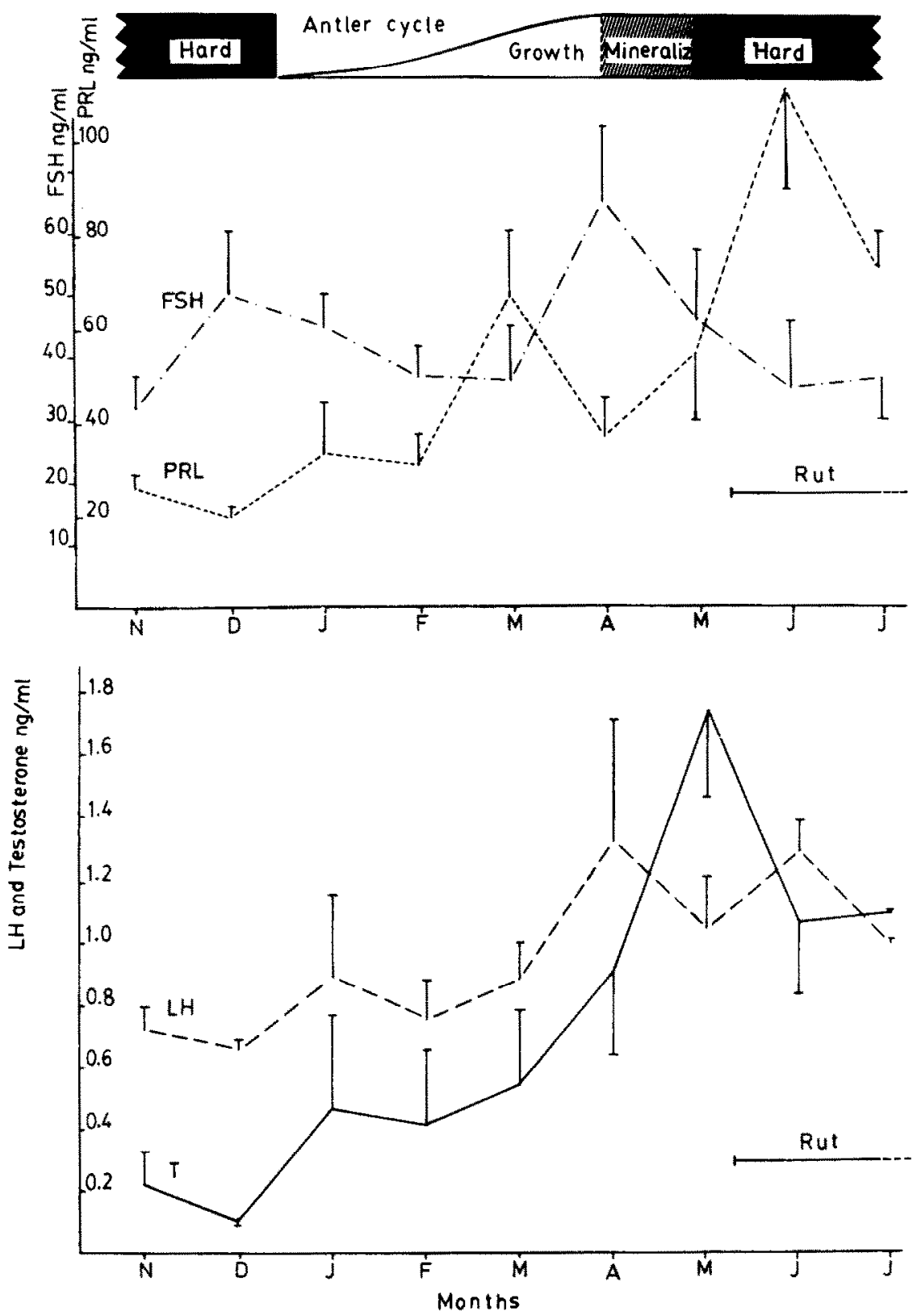

Fig. 1. Seasonal plasma levels of FSH, PRL, LH and T in adult male axis deer. $N=6$ from December to March, five from April to May and two in June. Vertical bars indicate standard errors. 
T exhibited a distinct seasonal variation. PRL levels in Nov, Dec, Feb, and April were lower than values in June and July. The June levels were higher than other months except March, May and July. Testosterone exhibited the most consistent seasonal fluctuation. Peak T levels in May were higher $(P<0.05)$ than any other month but April and June. Concentrations of $T$ in Nov and Dec were significantly lower than values in May, June and July.

\section{Antler cycle (actual, non-shifted)}

The antlers were cast from the end of December to the beginning of March. New antlers, which started to grow almost immediately after casting, were polished between March and June. The rutting season occurred in June and July.

\section{GnRH test}

GnRH increased plasma levels of both $\mathrm{LH}$ and T, however, as expected the response differed between individuals (Fig. 2). The relative elevation of $\mathrm{LH}$ was lower in the youngest individual (C), and his T levels remained virtually unchanged after GnRH administration.

\section{ACTH test}

Cortisol levels increased in all three bucks after ACTH injection (Fig. 3). Again, the relative elevation was lower in the youngest buck $(\mathrm{C})$ in which pretreatment cortisol levels were much higher than in the other two, more mature bucks.

\section{DISCUSSION}

\section{Seasonal cycles}

Reproduction in cervids of boreal and temperate regions is adjusted to coincide with the seasonal fluctuation of climatic conditions and food resources (Bubenik, 1984; Lincoln, 1985; Bubenik, 1986). The further north the deer populations, the more concise the peak of the rut and the corresponding peak of the fawning period (Bubenik et al., 1990). In contrast, in tropical areas, cervids are not under the restraint of cold, and the only factor affecting the timing of reproduction is the availability of food which is often determined by the local climatic factors, such as the timing of the rainy period. Therefore, deer populations of the same species residing on the same latitude may differ considerably in the timing of their reproductive cycles (Stuwe, 1985; Blouch, 1987; Fraser-Stewart, 1985; Mackenzie, 1985).

The synchronization of reproductive periods within the herd of tropical cervids observed either inthe northern limits of their range (Asdell, 1964; Mishra, 1982) or in populations transplanted to temperature regions (Chaplin, 1972; Chapman and Harris, personal communication) is most probably not photoperiodically-dependant. Tropical deer populations transplanted across several latitudes have often kept the breeding cycle of their previous locations (Mohr, 1918; Van Bemmel, 1949; Mackenzie, 1985). On the other hand, deer of boreal species moved across equator adjusted to the new photoperiodicity within several months (Otway, 1985). Indirect evidence for photoperiodic insensitivity of tropical deer resulted from a study utilizing melatonin. Male axis deer from the population kept in southern England did not respond to the melatonin treatment (Loudon and Curlewis, 1988) which in photoperiodically-dependant cervids [such as white-tailed deer (Odocoileus virginianus) or red deer (Cervus elaphus)] will quickly alter seasonality of pelage change and reproduction (Bubenik, 1983; Lincoln et al., 1984).

\section{Bucks:}
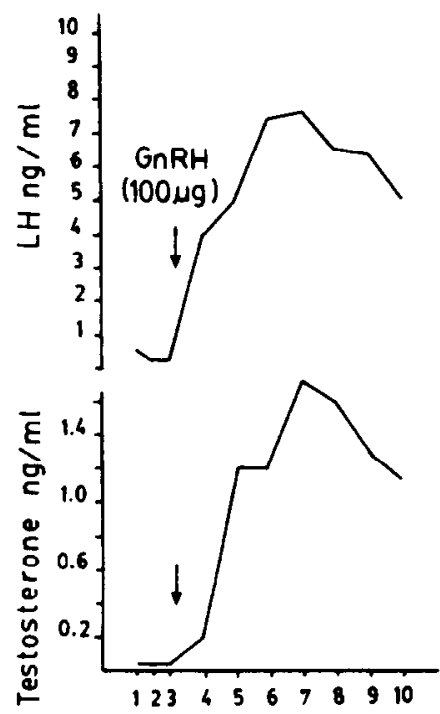

B
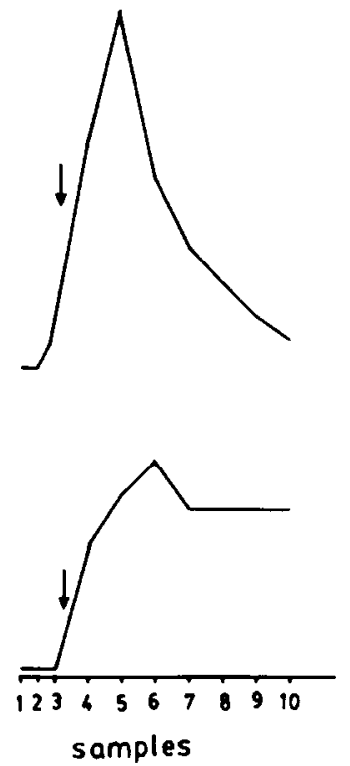

C
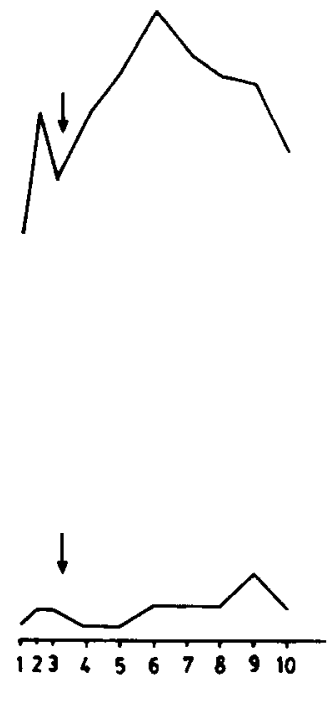

Fig. 2. Plasma levels of $\mathbf{L H}$ and $\mathrm{T}$ in three adult axis bucks injected i.m. with $100 \mu \mathrm{g}$ of $\mathrm{GnRH}$ at the time indicated by the arrow. 


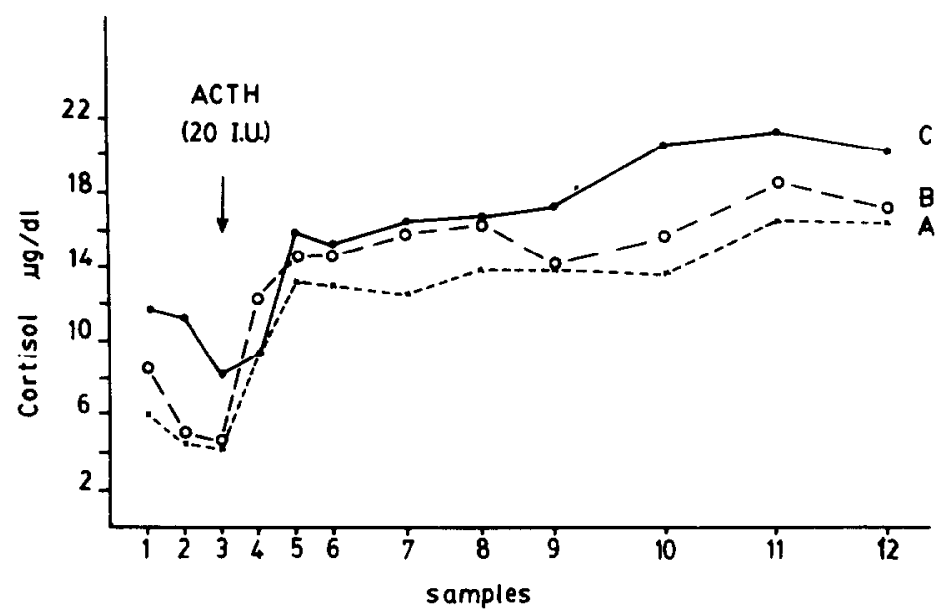

Fig. 3. Plasma levels of cortisol in three adult male axis deer afater i.m. administration of 20 I.U. of ACTH given at the time indicated by the arrow.

Any reproductive synchronization within the herd of tropical deer may occur because of the natural selection of individuals whose endogenous cycles best fit to local climatic conditions. Fawns born during the dry season would perish and so prevent a continuation of a genetic line unsuited for the local climatic environment. Therefore in cervids of tropical regions the fawning period is usually found at the beginning of the wet season, regardless of the latitude (Van Bemmel, 1952; Branan and Marchington, 1987).

The lack of synchronization in the reproductive cycles within the herd of axis deer in the Hamburg Zoo (Mohr, 1932), London Zoo (Asdell, 1964) or Whipsnade Park, England (Loudon and Curlewis, 1988) and muntjac populations in the London Zoo (Asdell, 1964) or in the wild in southern England (Dansie, 1983) may be due to the mixed origin of their stock obtained from various regions of India. On the other hand axis deer and muntjack populations which are synchronized (Chaplin, 1972; Ables, 1977; Dansie, 1983; Chapman and Harris-personal communication) may be more homogeneous in their origin or they may have developed their synchronization by a selection due to a climatic pressure

The lack of seasonal variation in levels of gonadotropins in this study (Fig. 1) is not surprising. Even in strictly seasonal boreal cervids, the mean levels of LH and FSH varies much less throughout the year than concentrations of T or PRL (Schams et al., 1986; Bubenik, 1986; Sempere, 1990). The maintenance of spermatogenesis and the progress of the rutting season is correlated less well with the gonadotropin levels than with concentrations of T (Schams et al., 1986; Bubenik et al., 1986; Sempere, 1990). Generally, LH and FSH levels in our axis deer were comparable only to low seasonal levels of short-day breeding boreal cervids, such as the white-tailed deer (Mirarchi et al., 1978; Bubenik et al., 1982); or red deer (Lincoln and Kay, 1979) but were close to mean seasonal levels found in the long-day breeding roe-deer (Capreolus capreolus) (Schams et al., 1986; Sempere, 1990).

Prolactin concentrations exhibited a seasonal variation comparable with the pattern observed in other cervids, tropical (van Mourik and Stelmasiak, 1990) or boreal (Mirarchi et al., 1978; Suttie et al., 1984; Bubenik et al., 1985; Sempere, 1990). Peak levels were observed during the longest days of the year (June), and trough values were detected in December (Fig. 1). As the peak concentrations of PRL in axis deer found in this study were comparable with peak levels of boreal cervids (Mirarchi, 1978 Suttie, 1984: Sempere, 1990), the minimal levels were at least 20 times higher than those in the boreal deer $(0.1-1.0 \mathrm{ng} / \mathrm{ml})$ and 4 times higher than $5 \mathrm{ng} / \mathrm{ml}$ detected in the rusa deer (Cervus rusa timorensis) farmed in southern Australia (van Mourik and Stelmasiak, 1990). Perhaps it is the relatively high PRL minimum which renders the seasonal PRL oscillation insufficient as a photoperiodic cue.

Testosterone concentrations exhibited the most pronounced variation, which correlated well with the antler cycle and the timing of the rut (Fig. 1). However, the large standard errors in almost all months indicate that there is still a considerable variation between individuals.

The relationship of T to PRL levels is typical for the long-day breeder (Schams et al., 1986; Sempere, 1990; van Mourik and Stelmasiak, 1990). It would be interesting to investigate whether blockade of PRL by bromocriptine would cause a shift in the timing of $T$ peak in axis deer as was observed in the roe-deer (Schams et al., 1986; Sempere, 1990).

\section{GnRH test}

Gonadotropin Releasing Hormone has been routinely utilized in testing and treatment of human pituitary-gonadal axis (Hodgen, 1983). Recently it has been used as a diagnostic tool for determination of reproductive potential in sheep (Haley et al., 1989) and white-tailed deer (Bubenik et al., 1987). In the red deer GnRH has been used for the testing of the gonadal axis during the individual phases of the antler cycle (Suttie et al., 1984).

The results of this study indicate that the response to $\mathrm{GnRH}$ in axis deer is very similar to findings in red deer or white-tailed deer (Suttie et al., 1984; Bubenik et al., 1987) not only in terms of time course of elevation but in terms of the relative and absolute increase as well (Fig. 2) 


\section{ACTH test}

In mammals, injection of ACTH induces secretion of glucocorticoids from the adrenal cortex. The sensitivity to $\mathrm{ACTH}$ varies between deer species; maximum cortisol secretion was elicited by 6 I.U. in rusa (van Mourik and Stelmasiak, 1984), by 20 I.U. in roe deer (Sempere and Bubenik, unpublished) and by the 20 40 I.U. in white-tailed deer (Smith and Bubenik, 1990).

In this study 20 I.U. elicitcd a response in axis deer which lasted longer than the $3 \mathrm{hr}$ of our experiment. Judging by the time course of the cortisol elevation it appears that the dose elicited a maximal response. However without testing various doses we cannot say this with absolute certainty. The peak levels of cortisol were in the range similar to those observed in white-tailed deer after 20 I.U. of ACTH (Smith and Bubenik, 1990).

The youngest buck exhibited the highest preadministration values of cortisol but also achieved the highest post-treatment cortisol levels (Fig. 3). This indicates a higher level of excitability of this buck. The relatively low pre-treatment levels in the two older deer suggest that these deer were well adjusted to captivity.

Acknowledgements-Authors would like to acknowledge the skilful technical assistance of Dr T. Dailey, J. Kidwell and V. Ramirez. The study was supported by the Caesar Kleberg Wildlife Research Institute in Kingsville, Texas and by NSERC, Canada.

\section{REFERENCES}

Ables E. D. (1977) The axis deer in Texas. Kleberg Studies in Natural Resources, Texas A \& M University.

Asdell S. A. (1964) Patterns of Mammalian Reproduction. 2nd. Ed. pp. 557-652., Cornell University Press, Ithaca, N.Y.

Blouch R. A. (1987) Reproductive seasonality of whitetailed deer on the Colombian Ilanos. In Biology and Management of the Cervidae (Edited by Wemmer C. M.), pp. 339-343. Smithsonian Inst. Press, Washington, D.C.

Branan W. V. and Marchington R. L. (1987) Reproductive ecology of white-tailed deer and red brocket deer in Suriname. In Biology and Management of the Cervidae (Edited by Wemmer C. M.). pp. 344-35i. Smithsonian Inst. Press, Washington, D.C.

Bubenik A. (1984) Ernahrung, Verhalten and Umwelt des Sichalenwildes. (Nutrition, Behavior and Environment of Big Game). BLV, Munchen, F.R.G.

Bubenik G. (1983) Shift of seasonal cycle in white-tailed deer by oral administration of melatonin. J. Exp. Zool. 225, 155-156.

Bubenik G. (1986) Regulation of seasonal endocrine rhythms in male boreal cervids. In Endocrine Regulation as Adaptive Mechanisms to the Environment (Edited by Assenmacher I. and Boissin J.), pp. 461-474, CNRS, France.

Bubenik G. A., Morris J. M., Schams D. and Claus A. (1982) Photoperiodicity and circannual levels of LH, FSH, and testosterone in normal and castrated male, white-tailed decr Can. J. Physiol. Pharmacol. 60, 788-793.

Bubenik G. A., Bubenik A. B., Schams D. and Leatherland J. F. (1983) Circadian and circannual rhythms of LH, FSH, testosterone ( $T$ ), prolactin, cortisol, $T_{3}$ and $T_{4}$ in plasma of mature, male, whitetailed deer. Comp. Biochem. Physiol. 76A, 3745.
Bubenik G. A., Schams D. and Leatherland J. F. (1985) Seasonal rhythms of prolactin and its role in the antler cycle of white-tailed deer. Royal Soc. New Zealand, Bull. 22, 257-262.

Bubenik G. A., Smith P. S. and Schams D. (1986) The effect of orally administered melatonin on the seasonality of deer pelage exchange, antler development, LH, FSH, prolactin, testosterone, $T_{3}, T_{4}$, cortisol and alkaline phosphatase. J. Pineal Res. 3, 331-349.

Bubenik G. A., Schams D. and Sempere A. (1987) Assessment of reproductive and antler performance of male white-tailed deer by Gn-RH stimulation test. Comp. Biochem. Physiol. 86A, 767-771.

Bubenik G., Brown R. D. and Schams D. (1990) The effect of latitude on the seasonal pattern of reproductive hormones in the male white-tailed deer. Comp. Biochem. Physiol. 97A, 253-257.

Chaplin R. E. (1972) The antler cycle of Muntjac deer in Britain. Deer 9, 938-941.

Dansie O. (1983) Muntjac. British Deer Soc. Publ. (2nd Ed.) Broadwater Press Ltd, Welwyn Garden City, Hertfordshire, U.K.

Fraser-Stewart J. W. (1985) Deer and development in South-west Papua-New Guinea. Royal Soc. New Zealand, Bull. 22, 381-385.

Haley C. S., Lee G., Fordyce M., Baxter G., Land R. B. and Webb R. (1989) Study of LH response to GnRH in the young male as a criterion of genetic merit for female reproduction in sheep. $J$. Reprod. Fert. 86, 119-133.

Hodgen G. D. (1983) Releasing hormones as diagnostic and therapeutic agents. Fertil. Steril. 39, 592--593.

Lincoln G. A. (1985) Seasonal breeding in deer. Royal Soc. New Zealand, Bull. 22, 165-179.

Lincoln G. A. and Kay R. N. B. (1979) Effect of season on the secretion of $\mathrm{LH}$ and testosterone in intact and castrated red deer stags (Cervus elaphus). J. Reprod. Fert. 55, 75-80.

Lincoln G. A., Fraser H. M. and Fletcher T. J. (1984) Induction of early rutting in male red deer (Cervus elaphus) by melatonin and its dependance on LHRH. J. Reprod. Fert. 72, 339-343.

Loudon A. S. I. and Curlewis J. D. (1988) Cycles of antler and testicular growth in an aseasonal tropical deer (Axis axis). J. Reprod. Fert. 83, 729-738.

Mackenzie A. R. (1985) Reproduction of farmed rusa deer (Cervus timorensis) in south-east Queensland, Australia. Roval. Soc. New Zealand, Bull. 22, 213-215.

Mirarchi R. E., Howland B. E., Scanlon P. F., Kirkpatrick R. L. and Sanford L. M. (1978) Seasonal variation in plasma of $\mathrm{LH}, \mathrm{FSH}$, prolactin and testosterone in adult male white-tailed deer. Can. J. Zool. 56, 121-127.

Mishra H. R. (1982) The ecology and behavior of chital (Axis axis) in the Royal Chitwan National Park, Nepal, with comparative study on Hog deer (Axis porcinus), sambar (Cervus unicolor) and barking deer (Muntjiacus muntjak). Ph.D. thesis, University of Edinburgh.

Mohr E. (1918) Biologie und Systematik der sechsender Hirsche Gattung Rusa. Archiv fur Naturgeschichte 84, 105-144.

Mohr E. (1932) Materialien uber die Hirschzuchte des ehemaligen Hamburger Zoo. Der Zool. Garten 3, 3-14.

Morris R. C. (1935) Growth and shedding of antlers in sambar (Cervus unicolor) and cheetal (Axis axis) in south India. J. Bombay Nat. Hist. Soc. 37, 484.

Otway W. (1985) Adaptation of the red deer after transport from the United Kingdom to New Zealand. Roval Soc. New Zealand, Bull. 22, 225-226.

Schams D. Barth D. and Karg H. (1986) Is antler growth in adult roe-deer (Capreolus capreolus) influenced by treatment with oestradiol-17 beta, an antiandrogen, or prolactin blocker? In Endocrine Regulation as Adaptive Mechanisms to the Environment (Edited by Assenmacher I. and Boisson J.), pp. 474-482. CNRS, France. 
Sempere A. (1990) The annual antler cycle of European roe deer (Capreolus capreolus) in relationship to the reproductive cycle. In Horns, Pronghorn and Antlers (Edited by Bubenik G. A. and Bubenik A. B.), pp. 349-412. Springer, New York.

Smith J. H. and Bubenik G. A. (1990) Plasma concentrations of glucocorticoids in white-tailed deer: The effect of acute ACTH and dexamethasone. Can. J. Zool. 86, 2123-2129.

Stuwe M. (1985) Aspects of structure and reproduction of white-tailed deer populations Odocoileus virginianus in Venezuela and Virginia. Saugetierkundl. Mitt. 32, 137-141.

Suttie J. M., Lincoln G. A. and Kay R. N. B. (1984)
Endocrine control of the antler growth in red deer stags. J. Reprod. Fert. 71, 7-15.

Van Bemmel A. C. V. (1949) Revision of the rusine deer in the Indo-Australian archipelago. Treubia 20, 191-266.

Van Bemmel A.C. V. (1952) Contribution to the knowledge of the genera Muntiacus and Arctogalidia in the Indoaustralian archipelago. Beaufortia 16, 1-50.

van Mourik S. and Stelmasiak T. (1984) Adrenal response to ACTH stimulation in rusa deer (Cervus rusa timorensis). Comp. Biochem. Physiol. 82A, 323-328.

van Mourik S. and Stelmasiak T. (1990) Endocrine mechanisms and antler cycle in rusa deer, Cervus rusa timorensis. In Horns, Pronghorns and Antlers (Edited by Bubenik G. A. and Bubenik A. B.), pp. 413-421. Springer, New York. 